\title{
ANALISIS MANAJEMEN LABA PADA PERUSAHAAN DI SEKTOR INDUSTRI FOOD AND BEVERAGES YANG TERDAFTAR DI BURSA EFEK INDONESIA TAHUN 2015-2016
}

\author{
Irene V. Runturambi ${ }^{1}$, Winston Pontoh ${ }^{2}$, Natalia T. Gerungai ${ }^{3}$ \\ ${ }^{1,2,3}$ Fakultas Ekonomi dan Bisnis, Jurusan Akuntansi, Universitas Sam Ratulangi, Jl.Kampus Bahu, Manado \\ 95115, Indonesia \\ E-mail: irenevkr@gmail.com
}

\begin{abstract}
Earnings management becomes an interesting topic of discussion. One of the thinking that as long as done in accordance with Indonesian Financial Accounting Standards it is difficult to say as earnings management. However, accountants tend to use accounting treatment to meet certain interests. The purpose of this study is to determine whether there is earnings management in companies in the Food and Beverages Industry Sector listed on the Indonesia Stock Exchange. The data used in this study is secondary data derived from the financial statements of companies listed on the Indonesia Stock Exchange in 2015-2016. The results showed that almost all companies that become the object of research to did earnings management, either by lowering or increasing the company's profit.
\end{abstract}

Keywords: Earnings Management

\section{PENDAHULUAN}

Salah satu sumber informasi bagi pihak eksternal dalam menilai kinerja perusahaan adalah laporan keuangan. Laporan keuangan merupakan ringkasan dari suatu proses pencatatan dan ringkasan dari transaksi-transaksi keuangan yang terjadi selama tahun buku bersangkutan. Laporan keuangan dibuat oleh manajemen dengan tujuan untuk mempertanggungjawabkan tugas-tugas yang dibebankan kepadanya oleh para pemilik perusahaan (Ilham Firdaus, 2013).

Kualitas pelaporan keuangan merupakan faktor terpenting dalam bertahannya suatu perusahaan. Pemilik atau pihak lain seperti kreditur atau investor dapat menilai kekuatan sebuah perusahaan melalui informasi dalam laporan keuangan untuk menentukan keputusan yang berkaitan dengan investasi. Dalam laporan keuangan laba merupakan komponen yang penting dimana laba digunakan untuk mengukur kinerja dan peningkatan suatu perusahaan.

Apabila terdapat kondisi ketika manajemen ternyata tidak berhasil mencapai target laba yang ditentukan, maka manajemen akan memanfaatkan fleksitabilitas yang diperbolehkan oleh standar akuntansi keuangan untuk pemilihan metode atau kebijakan akuntansi dalam melaporkan laba. Hal inilah yang memberi manajer peluang melakukan praktik pengelolaan laba untuk tujuan tertentu yang dikenal dengan istilah manajemen laba (earning management).

Manajemen laba merupakan salah satu topik akuntansi yang paling banyak dipelajari dan diteliti. Hal ini terjadi karena peran laba yang luar biasa penting dalam laporan keuangan, juga karena topik ini relatif abstrak sehingga pro-kontra terjadi di segala sisi. Mulai dengan perdebatan level konseptual hingga ke level paling teknis. Perdebatan level konseptual bisa kita lihat dari hal yang mendasar sekali, kenyataan bahwa angka laba, secara teknis, merupakan hasil "manipulasian". Sebab angka laba, yang didasarkan pada konsep akrual, ditentukan oleh para akuntan sendiri. Berbeda dengan, katakanlah, nilai pasar, yang pada kondisi paling idealnya memiliki nilai yang objektif. Misalnya, nilai pasar perusahaan publik yang sudah jelas tidak bisa diutak-atik lagi. Sementara itu, perdebatan di level teknis yang umum dijumpai adalah terkait model deteksi yang digunakan, apakah model tersebut cukup 
baik atau bahkan cukup mampu memprediksi nilai manipulasi laba yang terjadi (Arie Rahayu, 2016). Berdasarkan latar belakang maka rumusan masalah dalam penelitian ini adalah apakah terdapat manajemen laba pada perusahaan-perusahaan yang terdaftar di Bursa Efek Indonesia? Dimana tujuan penelitian ini adalah untuk menganalisis bagaimana manajemen laba pada perusahaan di Sektor Industri Food and Beverages yang terdaftar di Bursa Efek Indonesia.

\section{TINJAUAN PUSTAKA}

2.1 Konsep Manajemen Laba

\subsubsection{Pengertian Manajemen Laba}

Manajemen laba menurut Scott (2009:403) dalam V. Yamadita (2014) adalah "the choice by a manager of accounting policies so as ro achieve some specific objective". Yang artinya adalah manajemen laba merupakan keputusan manajer untuk memilih kebijakan akuntansi tertentu yang dianggap bisa mencapai tujuan yang diinginkan, baik itu untuk meningkatkan laba atau mengurangi kerugian yang dilaporkan.

Secara umum manajemen laba (earnings management) dapat didefinisikan sebagai upaya manajer perusahaan untuk mengintervensi atau mempengaruhi informasi-informasi dalam laporan keuangan dengan tujuan untuk mengelabuhi stakeholder yang ingin mengetahui kinerja dan kondisi perusahaan (Sulistyanto, 2008).

\subsubsection{Klasifikasi Manajemen Laba}

Menurut Hery (2009) dalam Astri Faradila (2013) manajemen laba dapat dibedakan menjadi dua kelompok, yaitu operating manipulations dan accounting manipulations. Manipulasi operasi terkait dengan tindakan mengubah keputusan operasional yang memengaruhi aliran dana dan pendapatan bersih untuk satu periode. Contoh manipulasi operasi antara lain: memasukkan pengeluaran periode mendatang ke dalam periode ini karena laba periode ini telah mencapai target, menawarkan diskon penjualan yang menarik pada akhir tahun untuk menaikkan laba, dan mempercepat produksi barang dengan lembur agar dapat dikirim sebelum akhir tahun. Manipulasi akuntansi terkait dengan penggunaan fleksibilitas dalam metode akuntansi untuk mengubah besarnya laba. Contoh manipulasi akuntansi antara lain: tidak mencatat pembelian barang yang diterima akhir tahun sampai tahun depan, membayar di muka pengeluaran tahun depan dan mencatatnya sebagai pengeluaran tahun ini, dan meminta pemasok agar tidak mengirimkan tagihan akhir tahun sampai tahun depan.

\subsubsection{Motivasi Manajemen Laba}

Scott (2006) mengemukakan beberapa motivasi terjadinya manajemen laba, yaitu:

\section{Bonus Purposes}

Manajer mempunyai informasi laba bersih sebelum dilaporkan dalam laporan keuangan, sementara pihak luar tidak bisa mengetahuinya sampai mereka membaca laporan keuangan. Karenanya manajer akan berusaha untuk mengatur laba bersih tersebut sehingga dapat memaksimalkan bonus mereka berdasarkan compensation plans perusahaan.

\section{Debt Convenant}

Kontrak hutang jangka panjang merupakan perjanjian untuk melindungi pemberi pinjaman kreditor dari tindakan-tindakan manajer terhadap kepentingan kreditor yang mana dapat menurunkan keamanan atau menaikan risiko bagi kreditor yang telah ada. Terdapat hipotesis debt convenant yang menyatakan bahwa semakin dekat suatu perusahaan ke pelanggaran perjanjian hutang, maka manajer akan cenderung memilih prosedur akuntansi yang dapat "memindahkan" laba periode mendatang ke periode berjalan.

\section{Political Motivation}


Beberapa motivasi politis yang mendorong perusahaan melakukan manajemen laba dengan cara menurunkan laba antara lain (a) untuk mengurangi biaya politis dan pengawasan dari pemerintah, (b) untuk memperoleh kemudahan dan fasilitas dari pemerintah, misalnya subsidi, perlindungan dari pesaing luar negeri, dan (c) untuk meminimalkan tuntutan serikat buruh.

\section{Taxation Motivation}

Contohnya yaitu, untuk persediaan, perusahaan akan memilih metode akuntansi LIFO, yang menghasilkan laba bersih paling rendah dibandingkan metode lainnya. Sehingga beban pajak yang dibayarkan akan menjadi rendah.

\section{Pergantian CEO}

Sebagai contoh, CEO yang mendekati masa akhir penugasan atau pension akan melakukan strategi memaksimalkan laba untuk meningkatkan bonusnya dan membuat CEO yang baru merasa sangat berat untuk mencapai tingkat laba tersebut. Demikian juga dengan CEO yang kurang berhasil memperbaiki kinerja perusahaan akan cenderung memaksimalkan laba untuk mencegah atau membatalkan pencatatannya.

6. Initial Public Offering (IPO)

Perusahaan yang akan go public belum memiliki nilai pasar, dan menyebabkan manajer perusahaan yang akan go public melakukan manajemen laba dengan harapan dapat menaikkan harga saham perusahaan.

7. Pentingnya Memberi Informasi Kepada Investor

Informasi mengenai kinerja perusahaan harus disampaikan kepada investor sehingga pelaporan laba perlu disajikan agar investor tetap menilai bahwa perusahaan tersebut dalam kinerja yang baik.

\subsubsection{Metode Manajemen Laba}

Ada dua metode yang bisa digunakan untuk manajemen laba menurut Healy dan Wahlen (1998), yaitu:

1. Seseorang bisa menggunakan fleksibilitas yang diperbolehkan dalam akuntansi yang berlaku umum prinsip (GAAP) untuk mengubah laporan laba- rugi tanpa mengubah arus kas (arus kas) yang mendasari, yang Healy dan Wahlen gambarkan sebagai penggunaan penilaian manajerial dalam pelaporan keuangan. Ini adalah disebut accounting earnings management.

2. Manajer dapat mengubah keputusan operasi, seperti jadwal pengiriman atau perawatan, agar mengelola arus kas yang mendasari yang akan mempengaruhi laporan pendapatan yang dilaporkan, yang digambarkan sebagai penataan transaksi oleh Healy dan Wahlen. Jenis manajemen ini biasanya disebut sebagai manajemen laba ekonomi.

\subsubsection{Teknik dan Pola Manajemen Laba}

Tabel 2.1

Teknik Manajemen Laba 


\begin{tabular}{|c|c|c|}
\hline No & Teknik & Tujuan \\
\hline 1 & Mengubah metode depresiasi & $\begin{array}{l}\text { Perusahaan dapat mengurangi beban depresiasi untuk menaikkan laba } \\
\text { periode berjalan, misalnya dengan mengubah metode saldo menurun } \\
\text { berganda ke metode garis lurus. }\end{array}$ \\
\hline 2 & Mengubah umur harta & $\begin{array}{l}\text { Perusahaan dapat memperkecil beban depresiasi dan amortisasi untuk } \\
\text { menaikkan laba periode berjalan dengan memperpanjang umur harta. }\end{array}$ \\
\hline 3 & $\begin{array}{l}\text { Mengubah nilai sisa } \\
\text { Harta }\end{array}$ & $\begin{array}{l}\text { Perusahaan dapat memperkecil beban depresiasi untuk menaikkan } \\
\text { laba periode berjalan dengan memperbesar nilai sisa harta. }\end{array}$ \\
\hline 4 & $\begin{array}{l}\text { Menetapkan cadangan } \\
\text { piutang tak tertagih }\end{array}$ & $\begin{array}{l}\text { Perusahaan dapat memperkecil biaya piutang tak tertagih untuk } \\
\text { menaikkan laba periode berjalan dengan menetapkan cadangan } \\
\text { piutang tak tertagih yang kecil. }\end{array}$ \\
\hline 5 & $\begin{array}{c}\text { Menetapkan cadangan } \\
\text { kewajiban jaminan garansi }\end{array}$ & $\begin{array}{c}\text { Dengan menetapkan kecil cadangan kewajiban jaminan garansi, } \\
\text { perusahaan dapat memperkecil biaya jaminan garansi untuk } \\
\text { menaikkan laba periode berjalan. }\end{array}$ \\
\hline 6 & $\begin{array}{l}\text { Menentukan adanya } \\
\text { kerusakan harta }\end{array}$ & $\begin{array}{l}\text { Perusahaan dapat membebankan kerugian pada periode berjalan untuk } \\
\text { menyimpan laba periode berjalan sebagai simpanan laba periode- } \\
\text { periode mendatang atau menangguhkan beban periode sebelumnya. }\end{array}$ \\
\hline 7 & $\begin{array}{c}\text { Mengestimasi tahap } \\
\text { penyelesaian kontrak } \\
\text { Dengan metode persentase } \\
\text { penyelesaian }\end{array}$ & $\begin{array}{c}\text { Dengan menetapkan persentase penyelesaian yang besar, perusahaan } \\
\text { dapat mengakui pendapatan lebih besar untuk menaikkan laba } \\
\text { periode berjalan. }\end{array}$ \\
\hline 8 & $\begin{array}{l}\text { Mempertimbangkan } \\
\text { jumlah persediaan yang } \\
\text { dihapus }\end{array}$ & $\begin{array}{c}\text { Dengan menurunkan jumlah persediaan yang seharusnya dihapuskan, } \\
\text { perusahaan dapat mengurangi beban tahun ini untuk menaikkan laba } \\
\text { periode berjalan. }\end{array}$ \\
\hline 9 & $\begin{array}{l}\text { Mengakui pendapatan } \\
\text { atas pengiriman barang ke } \\
\text { kantor perwakilan }\end{array}$ & $\begin{array}{l}\text { Dengan mengakui pendapatan atas pengiriman barang ke kantor } \\
\text { perwakilan yang sebenarnya belum terjual, perusahaan mengakui } \\
\text { pendapatan lebih besar untuk menaikkan laba periode berjalan. }\end{array}$ \\
\hline 10 & $\begin{array}{l}\text { Tidak menutup periode } \\
\text { Akuntansi }\end{array}$ & $\begin{array}{c}\text { Dengan tetap membuka periode akuntansi, perusahaan masih tetap } \\
\text { dapat mencatat penjualan periode berikutnya untuk menaikkan laba } \\
\text { periode berjalan. Teknik ini biasanya dilakukan dengan } \\
\text { memundurkan tanggal pada computer. }\end{array}$ \\
\hline
\end{tabular}

Sebagian besar teknik manajemen laba dalam tabel di atas dapat digunakan dalam arah sebaliknya. Misalnya, perusahaan menangguhkan pembebanan kerugian atas kerusakan harta. Dengan menangguhkan pembebanan kerugian atas kerusakan harta, perusahaan dapat meangguhkan kerugian pada periode ini dan dapat mempertahankan laba. Pola manajemen laba menurut Scott (2000) dalam Nieken Herma Sari (2014) dapat dilakukan dengan cara:

\section{Taking a Bath}

Pola ini terjadi pada saat reorganisasi termasuk pengangkatan CEO baru dengan melaporkan kerugian dalam jumlah besar. Teknik ini mengakui adanya biaya-biaya pada periode yang akan datang dan kerugian periode berjalan ketika keadaan buruk yang tidak menguntungkan tidak bisa dihindari pada periode berjalan. Konsekuensinya manajemen "menghapus" beberapa aktiva, membebankan perkiraan-perkiraan mendatang. Akibatnya laba pada periode berikutnya akan lebih tinggi dari seharusnya.

\section{Income Minimization}

Dilakukan pada saat perusahaan memperoleh profitabilitas yang tinggi dengan tujuan agar tidak mendapat perhatian secara politis. Kebijakan yang diambil dapat berupa penghapusan atas barang modal dan aktiva berwujud, pembebanan pengeluaran iklan, riset dan pengembangan yang cepat, memilih metode succesfull-effort untuk biaya eksplorasi gas dan minyak bumi dan sebagainya.

\section{Income Maximization}

Dilakukan pada saat laba menurun. Tindakan atas income maximization ini bertujuan untuk melaporkan net income yang tinggi untuk tujuan bonus yang lebih besar. Pola ini dilakukan oleh perusahaan yang melakukan pelanggaran perjanjian hutang.

\section{Income Smoothing}


Dilakukan perusahaan dengan cara meratakan laba yang dilaporkan sehingga dapat mengurangi fluktuasi laba yang terlalu besar karena pada umumnya investor lebih menyukai laba yang relatif stabil.

\subsubsection{Model-Model Pengukur Manajemen Laba}

Pengukuran manajemen laba yang dilakukan untuk mengetahui ada atau tidaknya manajemen laba dalam suatu perusahaan. Manajemen laba (earnings management) diukur dengan proksi discretionary accrual (DA). Beberapa model menggunakan asumsi bahwa perhitungan akrual yang tidak normal diawali dengan perhitungan total akrual.

Total akrual adalah selisih antara laba dan arus kas yang berasal dari aktivitas operasi. Total akrual sebuah perusahaan dibedakan menjadi discretionary accrual (tingkat akrual yang normal) dan non-discretionary accrual (tingkat akrual yang tidak normal). Tingkat akrual yang tidak normal ini merupakan tingkat akrual hasil rekayasa laba yang dilakukan oleh manajer. Perhitungan total akrual dengan pendekatan arus kas dan laporan laba rugi dihitung dengan rumus sebagai berikut (Sloan, 1996):

Ket. $\quad$ TA $=$ Total akrual

$$
\text { TA = Earn }- \text { CFO }
$$

Earn = Laba

$\mathrm{CFO}=$ Arus kas operasi

Ada lima macam model yang dapat digunakan untuk men-deteksi adanya earnings management yang ditunjukkan dengan adanya discretionary accruals. Kelima model tersebut mengungkap adanya earnings management yang dilakukan oleh Dechow et al. pada tahun 1995.

\section{The Healy Model}

Model Healy (1999) menguji manajemen laba dengan membandingkan rata- rata total akrual yang dibagi dengan total akrual periode sebelumnya. Healy (1985) menanggap non discretionary accrual (NDA) tidak dapat diobservasi. Model untuk non discretionary accrual adalah sebagai berikut:

$$
\text { NDA }=0 \quad \text { sehingga } \quad \text { TA }=\text { NDA }
$$

Healy memprediksi bahwa manajemen laba terjadi setiap periode. Model diskresioner menurutnya sebangai berikut:

$$
\text { DAt }=\text { TAt } / \text { At-1 }
$$

Ket: $\quad$ DAt $=$ Discretionary accruals pada periode $\mathrm{t}$

TAt $=$ Total accrual pada periode $\mathrm{t}$

At- $1=$ Total asset pada 1 tahun sebelum tahun $\mathrm{t}$

\section{The Angelo Model}

DeAngelo (1986), menguji adanya earnings management dengan menghitung perbedaan pada total akrual dan dengan mengasumsikan bahwa jika perbedaan diharapkan tidak ada, berarti tidak terdapat earnings management. Model ini menggunakan total accruals periode sebelumnya yang dibagi dengan selisih total assets periode sebelumnya untuk mengukur non-discretionary accruals. Model non-discretionary yang digunakan oleh DeAngelo adalah sebagai berikut:

$$
\text { NDA }=\text { TA - }
$$

Ket. NDA = Estimasi non-discretionary accruals

TA $-\quad=$ Total accruals dibagi total asset 1 tahun sebelum tahun $\mathrm{t}$

\section{The Jones Model}

Jones (1991) mengusulkan sebuah model yang menggunakan asumsi bahwa nondiscretionary accruals bersifat konstan. Model Jones mengontrol pengaruh perubahan 
lingkungan ekonomi perusahaan pada non-discretionary accruals. Model Jones untuk nondiscretionary accruals menggunakan persamaan:

TAit/Ait-1 $=\alpha 1(1 /$ Ait-1) $+\alpha 2(\Delta R E V i t /$ Ait-1) $+\alpha 3($ PPEit / Ait-1) + e

Ket. $\quad \triangle \mathrm{REV}=$ Pendapatan pada tahun $\mathrm{t}$ dikurangi pendapatan tahun $\mathrm{t}-1$..

$\mathrm{PPE}=$ Gross properti plant dan equipment pada tahun $\mathrm{t}$ dibagi total aset tahun $\mathrm{t}-1$.

A - = Total aset 1 tahun sebelum tahun $\mathrm{t}$.

a1, a2, a3 = Parameter perusahaan tertentu.

\section{The Modified Jones Model}

Modifikasi model yang dilakukan oleh Jones didesain untuk mengurangi adanya dugaan pada model Jones dalam kesalahan mengukur discretionary accruals, ketika discretionary dilakukan terhadap pendapatan. Dalam model yang dimodifikasi ini, nondiscretionary accruals adalah estimasi pada periode kejadian (event period), yaitu selama periode earnings management diperkirakan terjadi. Model perhitungannya adalah sebagai berikut:

TAit/Ait-1 $=\alpha 1(1 /$ Ait-1 $)+\alpha 2((\Delta R E V i t-\Delta R E C i t) /$ Ait-1 $)+\alpha 3($ PPEit/Ait-1 $)+e$

Persamaan total akrual diatas diestimasi dengan metode Ordinary Least Square (OLS). Estimasi $\alpha 1, \alpha 2, \alpha 3$ diperoleh dari regresi OLS tersebut dan digunakan untuk menghitung non-discretionary accrual sebagai berikut:

NDAit $=\alpha 1(1 /$ Ait-1) $+\alpha 2((\Delta R E V i t-\Delta R E C i t) /$ Ait-1) $+\alpha 3$ (PPEit / Ait-1)

Selanjutnya discretionary accrual (DA) dapat dihitung sebagai berikut:

\section{DAit $=($ TAit $/$ Ait-1) - NDAit}

Ket: $\quad$ DAit $=$ Discretionary Accruals perusahaan i pada tahun $\mathrm{t}$

$\triangle \mathrm{REC}=$ net receivable (piutang bersih) pada tahun $\mathrm{t}$ dikurangi net receivable pada tahun $\mathrm{t}-1$ dibagi total aset pada tahun $\mathrm{t}-1$.

Estimasi a1a2, a3 dan non-discretionary accruals selama periode estimasi (ketika tidak terdapat systematic earnings management yang diperkirakan) diperoleh dari Model Jones pertama. Hanya dilakukan penyesuaian secara relatif terhadap model Jones pertama yang mengubah pendapatan yang disesuaikan dengan menggunakan piutang dagang pada periode terjadinya. Pada model Jones pertama secara implisit mengasumsikan bahwa discretionary tidak dilakukan terhadap pendapatan pada periode estimasi lainnya atau pada periode terjadinya. Pada versi modifikasi, model Jones mengasumsikan bahwa semua perubahan dari penjualan kredit pada periode terjadinya (event period) menghasilkan earnings management. Hal tersebut berdasarkan alasan bahwa lebih mudah untuk memodifikasi earnings dengan melakukan discretionary melalui pengakuan pendapatan dari penjualan tunai. Jika modifikasi ini berhasil, selanjutnya estimasi earnings management tidak akan bias pada sampel apabila earnings management dilakukan melalui modifikasi pendapatan.

\subsubsection{Discretionary Accrual}

Akrual merupakan semua kejadian yang bersifat operasional pada suatu tahun yang berpengaruh terhadap arus kas, perubahan piutang dan hutang, serta perubahan persediaan. Sedangkan untuk biaya depresiasi merupakan akrual negatif. Akuntan memperhitungkan akrual untuk menandingkan biaya dengan pendapatan melalui perlakuan transaksi yang berkaitan dengan laba bersih sesuai dengan yang diharapkan.

\subsection{Konsep Akuntansi \\ 1.2.1 Definisi Akuntansi}


Akuntansi adalah seni pencatatan, pengklasifikasian, dan pengikthisaran dalam cara yang signifikan dan satuan mata uang, transaksi-transaksi dan kejadian-kejadian yang paling tidak sebagian diantaranya, memiliki sifat keuangan, dan selanjutnya menginterpretasikan hasilnya (American institute of certified Public Accountants dalam Belkaoui, 2015:50). Menurut A Statement of Basic Accounting Theory (ASOBAT) yang diterbitkan oleh American Accounting Association (AAA) pada tahun 1966, akuntansi didefinisikan sebagai proses mengidentifikasi, mengukur, dan menyampaikan informasi ekonomi bagi para penggunanya dalam mempertimbangkan berbagai alternatif yang ada dan membuat kesimpulan (dalam Hery, 2013;3).

\subsubsection{Teori Agensi}

Teori keagenan menggambarkan perusahaan sebagai suatu titik temu antara pemilik perusahaan (principal) dengan manajemen (agent). Pada teori keagenan yang disebut prinsipal adalah pemegang saham dan yang disebut agen adalah manajemen yang mengelola perusahaan.

Menurut Jensen dan Meckling (1976) dalam Shalihatunnisa (2017) menyatakan bahwa hubungan keagenan merupakan sebuah kontrak yang terjadi antara manajer (agent) dengan pemilik perusahaan (principal). Wewenang dan tanggungjawab agent maupun principal diatur dalam kontrak kerja atas persetujuan bersama. Dalam hal ini, principal mendelegasikan beberapa kewenangan kepada agent untuk mengambil keputusan. Jika kedua belah pihak berhubungan untuk memaksimalisasi utilitas, maka ada kemungkinan agen tidak selalu bertindak untuk kepentingan utama prinsipal.

\subsection{Konsep Akuntansi Manajemen}

Akuntansi manajemen adalah salah satu cabang ilmu akuntansi yang menghasilkan informasi untuk manajemen atau pihak intern perusahaan. Pengguna utama informasi akuntansi manajemen adalah para manajer, yang bertugas merencanakan kegiatan, menerapkan rencana, dan mengarahkan serta mengendalikan kegiatan organisasi tersebut atau berjalan sesuai rencana. Informasi yang dihasilkan oleh akuntansi manajemen akan dimanfaatkan oleh para manajer untuk membantu melaksanakan tugasnya.

\subsection{Penelitian Terdahulu}

Anggie Febriyanti (2014) dalam penelitian berjudul Manajemen Laba: Pro-Kontra Pemaknaan Antara Kreditur Dan Debitur Dalam Proses Pembiayaan Kredit. Tujuan penelitian mengungkap terjadinya manajemen laba serta berbagai pertimbangan debitur maupun kreditur dalam menyikapinya. Hasil penelitian menunjukkan bahwa manajemen laba memang terjadi.

Astri Faradila (2013) dalam penelitian berjudul Analisis Manajemen Laba Pada Perbankan Syariah. Tujuan penelitian mengungkap terjadinya manajemen laba pada perbankan syariah. Hasil penelitian mengungkap terjadi manajemen laba pada perbankan syariah.

\section{METODE PENELITIAN}

\subsection{Jenis Penelitian}

Dalam penelitian ini penulis menggunakan jenis penelitian kualitatif yang bersifat deskriptif, untuk mengetahui atau menggambarkan keyataan dari kejadian yang di teliti sehingga memudahkan penulis untuk mendapatkan data yang objektif dalam rangka memahami Manajemen Laba. Dalam penelitian ini menggunakan penelitian kulatiatif karena permasalahan berhubungan dengan manusia yang secara fundamental bergantung pada pengamatan. 


\subsection{Jenis Data dan Sumber Data}

\subsubsection{Jenis Data}

Menurut Kuncoro (2013) data terbagi dalam dua jenis, yaitu:

1. Data kuantitatif, yaitu data yang berbentuk angka-angka atau data kualitatif yang diangkakan. Data kuantitatif yang digunakan dalam penelitian ini adalah laporan keuangan dan daftar harga saham harian perusahaan di sektor industri food and beverages yang terdaftar di BEI pada tahun 2015 - 2016.

2. Data kualitatif, yaitu data yang berbentuk kata, kalimat, skema atau gambar. Data kualitatif yang digunakan dalam penelitian ini adalah daftar perusahaan perusahaan di sektor industri food and beverages yang terdaftar di BEI pada tahun 2015 - 2016.

\subsubsection{Sumber Data}

Sumber data dibedakan menjadi dua bagian, yaitu:

1. Sumber Primer

Menurut Sugiono (2015:225) sumber primer adalah sumber data yang secara langsung memberikan data kepada pengumpul data (tidak melalui media perantara).

2. Data Sekunder

Data sekunder ialah data yang diambil dari artikel jurnal dari internet, literatur atau informasi lain yang berhubungan dengan penelitian ini (data yang telah disediakan oleh pihak ketiga dan tidak berasal dari sumber langsung).

Data yang digunakan dalam penelitian ini adalah data sekunder meliputi annual report dan data harga saham harian perusahaan di sektor industri food and beverages yang terdaftar di BEI pada tahun 2015 - 2016 dengan mengunduh melalui situs resmi BEI www.idx.co.id.

\subsection{Tempat dan Waktu Penelitian}

Penelitian ini dilakukan di Bursa Efek Indonesia (BEI) yang berada di kota Manado, dan juga pencarian data dengan mengunduh annual report yang diakses melalui situs resmi BEI www.idx.co.id. Waktu penelitian dilaksanakan pada bulan Agustus sampai bulan Oktober 2017.

\subsection{Prosedur Penelitian}

Prosedur penelitian ini meliputi langkah-langkah sebagai berikut:

1. Perumusan Masalah. Langkah pertama yang dilakukan adalah dengan melihat dan menggali inti permasalahan yang diangkat untuk diteliti lebih lanjut. Kemudian berdiskusi dengan pihak Laboratorium Akuntansi FEB Unsrat untuk menguatkan inti permasalahan serta metode yang tepat untuk melanjutkan penelitian.

2. Pengumpulan Data. Tahapan pengumpulan data dilakukan dengan mengunduh langsung melalui situs resmi BEI www.idx.co.id.

3. Mengolah Data. Setelah semua data-data yang dibutuhkan terkumpul, langkah berikutnya dimulai dengan mengolah data-data tersebut dan berkonsultasi dengan dosen pembimbing penelitian dalam menjawab permasalahan yang telah dirumuskan sebelumnya.

4. Menarik Kesimpulan. Hasil analisis dan perhitungan data tersebut kemudian diuraikan dalam bentuk kalimat berupa keterangan-keterangan yang dihasilkan dalam penelitian dan pembahasan digunakan sebagai acuan dalam penarikan kesimpulan yang merupakan rangkuman dari keseluruhan penelitian ini.

\subsection{Teknik Pengambilan Data}

Metode pengumpulan data dalam penelitian ini adalah metode dokumentasi. Metode dokumentasi yang digunakan dalam penelitian ini adalah data laporan keuangan perusahaan 
perusahaan di sektor industri food and beverages yang terdaftar di BEI pada tahun 2015 2016 yang bersumber dari website IDX (Indonesia Stock Exchange).

\subsection{Metode Analisis Data}

Dalam penelitian ini, analisis data kualitatif merupakan upaya berlanjut, berulang dan terus-menerus. Masalah reduksi data, penyajian data, dan penarikan kesimpulan/verifikasi menjadi gambaran keberhasilan secara berurutan sebagai rangkaian kegiatan analisis yang saling topang. Namun dua hal lainnya itu senantiasa merupakan bagian dari lapangan. Sehingga Metode analisis yang digunakan dalam penelitian ini adalah analisis deskriptif, yang disesuaikan untuk mengetahui bagaimana analisis Manajemen Laba pada perusahaanperusahaan di sektor food and beverages yang terdaftar di BEI.

\section{HASIL PENELITIAN DAN PEMBAHASAN \\ 4.1 Gambaran Umum Perusahaan}

\subsubsection{Sejarah Bursa Efek Indonesia}

Secara historis, pasar modal telah hadir jauh sebelum Indonesia merdeka. Pasar modal atau bursa efek telah hadir sejak jaman kolonial Belanda dan tepatnya pada tahun 1912 di Batavia. Pasar modal ketika itu didirikan oleh pemerintah Hindia Belanda untuk kepentingan pemerintah kolonial atau VOC.

Meskipun pasar modal telah ada sejak tahun 1912, perkembangan dan pertumbuhan pasar modal tidak berjalan seperti yang diharapkan, bahkan pada beberapa periode kegiatan pasar modal mengalami kevakuman. Hal tersebut disebabkan oleh beberapa faktor seperti perang dunia ke I dan II, perpindahan kekuasaan dari pemerintah kolonial kepada pemerintah Republik Indonesia, dan berbagai kondisi yang menyebabkan operasi bursa efek tidak dapat berjalan sebagimana mestinya. Pemerintah Republik Indonesia mengaktifkan kembali pasar modal pada tahun 1977, dan beberapa tahun kemudian pasar modal mengalami pertumbuhan seiring dengan berbagai insentif dan regulasi yang dikeluarkan pemerintah.

\subsubsection{Visi dan Misi Bursa Efek Indonesia}

Visi: $\quad$ Menjadi bursa yang kompetitif dengan kredibilitas tingkat dunia.

Misi: Menciptakan daya saing untuk menarik investor dan emiten, melalui pemberdayaan Anggota Bursa dan Partisipan, penciptaan nilai tambah, efisiensi biaya serta penerapan good governance.

\subsubsection{Jajaran Direksi Bursa Efek Indonesia}

\section{I Nyoman Tjager}

Komisaris Utama BEI sejak Agustus 2008. Lahir di Tabanan, Bali 30 Maret 1950. Perjalanan karirnya selama lebih dari 30 tahun dimulai di Biro Hukum Bapepam-LK, 19781997, dengan jabatan terakhir sebagai Kepala Biro Perundang-undangan dan Bantuan Hukum hingga menjadi Komisaris Utama BEI tahun 2008. Memperoleh gelar Sarjana Hukum dari Fakultas Hukum Universitas Gajah Mada, Yogyakarta; Master di bidang Ekonomi dari Fordham University, New York, AS; Doktor dari Program Doktor Hukum, Universitas Gajah Mada, Yogyakarta, Indonesia. Pengajar di program Magister Hukum Bisnis Universitas Gajah Mada dan Fakultas Hukum Program Notariat Universitas Indonesia.

\section{Chaeruddin Berlian}

Komisaris BEI sejak Juni 2008. Lahir di Plaju, 20 Juli 1958. Sebelumnya menjabat sebagai Komisaris Pefindo, 2005-2007. Memperoleh gelar Sarjana Ekonomi dari Fakultas Ekonomi Universitas Diponegoro, Semarang, 1982; Magister Manajemen Keuangan, Universitas Krisnadwipayana, Indonesia, 2003.

\section{Felix Oentoeng Soebagjo}

Komisaris BEI sejak Juni 2008. Lahir di Cilacap, Jawa Tengah, 13 Maret 1948.Memperoleh gelar Sarjana Hukum dari Universitas Indonesia, 1976, LLM dari 
University of California, Berkeley, dan Doktor di bidang Ilmu Hukum Universitas Gajah Mada, 2004 dan Guru Besar FHUI, 2008.

\section{Johnny Darmawan Danusasmita}

Komisaris BEI sejak Juni 2008. Lahir di Jakarta, 1 Agustus 1952.Sampai saat ini masih menjabat sebagai Direktur PT Astra International, Presiden Direktur PT Toyota Astra Motor, Vice President PT Toyota Motor Manufacturing Indo, Presiden Komisaris PT Astra Otopart Tbk, dan Komisaris antara lain di PT Serasi Autoraya, PT Toyota Astra Fin Service, PT Astratel, PT Intertel, PT Brahmayasa Bahtera dan PT Toyofuji Shipping.Memperoleh gelar Sarjana Akuntansi dari Universitas Trisakti, Jakarta.

\section{Suwantara Gotama}

Komisaris BEI sejak Juni 2011. Lahir di Jember, 19 April 1963, meraih gelar Bachelor of Arts di bidang Business administration dari University of Washington, Seattle pada tahun 1998. Pernah menjabat sebagai Head of Dealing \& Floor Trading PT Peregrine Sewu Securities, Assistant Treasurer PT Gunung Sewu Kencana, dan sejak 1994 hingga sekarang sebagai Presiden Direktur PT CLSA Indonesia.

\section{Tabel 4.1}

Daftar Perusahaan di Sektor Food and Beverages di BEI Yang Digunakan

\begin{tabular}{|l|l|l|}
\hline No & Kode Saham & \multicolumn{1}{c|}{ Nama Perusahaan } \\
\hline 1 & ADES & PT Akasha Wira International Tbk \\
\hline 2 & AISA & PT Tiga Pilar Sejahtera Food Tbk \\
\hline 3 & ALTO & PT Tri Banyan Tirta Tbk \\
\hline 4 & CEKA & PT Cahaya Kalbar Tbk \\
\hline 5 & DLTA & PT Delta Djakarta Tbk \\
\hline 6 & ICBP & PT Indofood CBP Sukses Makmur Tbk \\
\hline 7 & INDF & PT Indofood Sukses Makmur Tbk \\
\hline 8 & MLBI & PT Multi Bintang Indonesia Tbk \\
\hline 9 & MYOR & PT Mayora Indah Tbk \\
\hline 10 & PSDN & PT Prashida Aneka Niaga Tbk \\
\hline 11 & ROTI & PT Nippon Indosari Corprindo Tbk \\
\hline 12 & SKBM & PT Sekar Bumi Tbk \\
\hline 13 & SKLT & PT Sekar Laut Tbk \\
\hline 14 & STTP & PT Siantar Top Tbk \\
\hline 15 & ULTJ & PT Ultrajaya Milk Industry and Trading Company Tbk \\
\hline
\end{tabular}

\subsection{Pembahasan}

Dalam penelitian ini untuk menghitung manajemen laba peneliti menggunakan empat model perhitungan yang berbeda, yaitu: The Healy Model, The Angelo Model, The Jones Model, dan The Modified Jones Model.

Untuk mendapatkan hasil dari keempat model yang telah disebutkan, tahapan yang perlu dilakukan ialah:

1. Memasukkan data-data dari laporan keuangan perusahaan-perusahan dari tahun 20152016.

2. Pertama-tama menghitung Total Akruals.

Tabel 4.2. Total Akruals

\begin{tabular}{|c|c|c|}
\hline Nama Perusahaan & Total_Akruals 2015 & Total Akruals 2016 \\
\hline ADES & -9.659 & -85.156 \\
\hline
\end{tabular}


Jurnal Riset Akuntansi Going Concern 12(2), 2017, 857-873

\begin{tabular}{|c|c|c|}
\hline AISA & -25.435 & 255.648 \\
\hline ALTO & -46.943 .817 .709 & -46.945 .439 .902 \\
\hline CEKA & -62.064 .923 .254 & 73.609 .696 .264 \\
\hline DLTA & -54.580 .215 & -5.342 .238 \\
\hline ICBP & -562.385 & -953.663 \\
\hline INDF & -504.112 & -1.908 .697 \\
\hline MLBI & -422.323 & -266.340 \\
\hline MYOR & -1.086 .552 .369 .395 & 729.361 .930 .490 \\
\hline PSDN & -19.892 .902 .745 & -61.091 .474 .355 \\
\hline ROTI & -284.973 .140 .174 & -134.925 .057 .587 \\
\hline SKBM & -22.319 .427 .862 & 56.379 .691 .407 \\
\hline SKLT & -9.600 .131 .510 & 19.005 .080 .776 \\
\hline STTP & -9.137 .921 .557 & 7.990 .591 .812 \\
\hline ULTJ & -146.363 .067 .861 & -69.283 .010 .094 \\
\hline
\end{tabular}

3. Menghitung rumus pertama untuk model Healy.

Tabel 4.3 The Healy Model

\begin{tabular}{|c|c|c|}
\hline Nama Perusahaan & Healy Model 2015 & Healy Model 2016 \\
\hline ADES & $-0,019131847$ & $-0,130362632$ \\
\hline AISA & $-0,003449343$ & 0,028214167 \\
\hline ALTO & $-0,037886833$ & $-0,039776583$ \\
\hline CEKA & $-0,04833152$ & 0,049541256 \\
\hline DLTA & $-0,054720125$ & $-0,005145069$ \\
\hline ICBP & $-0,022468897$ & $-0,035905143$ \\
\hline INDF & $-0,005856507$ & $-0,02078476$ \\
\hline MLBI & $-0,189293297$ & $-0,126777076$ \\
\hline MYOR & $-0,105511039$ & 0,064302232 \\
\hline PSDN & $-0,031956044$ & $-0,098471288$ \\
\hline ROTI & $-0,132985161$ & $-0,049855478$ \\
\hline SKBM & $-0,034181058$ & 0,073748663 \\
\hline SKLT & $-0,028492758$ & 0,05039655 \\
\hline STTP & $-0,005374603$ & 0,004162703 \\
\hline ULTJ & $-0,050156403$ & $-0,019571494$ \\
\hline
\end{tabular}

4. Menghitung rumus kedua untuk model Angelo

Tabel 4.4. The Angelo Model 


\begin{tabular}{|c|c|c|}
\hline Nama Perusahaan & Angelo Model 2015 & Angelo Model 2016 \\
\hline ADES & $-0,019131847$ & $-0,130362632$ \\
\hline AISA & $-0,003449343$ & 0,028214167 \\
\hline ALTO & $-0,037886833$ & $-0,039776583$ \\
\hline CEKA & $-0,04833152$ & 0,049541256 \\
\hline DLTA & $-0,054720125$ & $-0,005145069$ \\
\hline ICBP & $-0,022468897$ & $-0,035905143$ \\
\hline INDF & $-0,005856507$ & $-0,02078476$ \\
\hline MLBI & $-0,189293297$ & $-0,126777076$ \\
\hline MYOR & $-0,105511039$ & 0,064302232 \\
\hline PSDN & $-0,031956044$ & $-0,098471288$ \\
\hline ROTI & $-0,132985161$ & $-0,049855478$ \\
\hline SKBM & $-0,034181058$ & 0,073748663 \\
\hline SKLT & $-0,028492758$ & 0,05039655 \\
\hline STTP & $-0,005374603$ & 0,004162703 \\
\hline ULTJ & $-0,050156403$ & $-0,019571494$ \\
\hline
\end{tabular}

5. Mencari koefisien $\alpha$ yang terdapat dalam kedua rumus berikutnya dengan menggunakan program SPSS dan dihitung dengan menggunakan Regresi Linear Berganda.

a. Untuk mencari koefisien $\alpha$ dalam TA (Total Akrual)

Coefficients $^{\mathrm{a}}$

Tabel 4.5. Koefisien dalam Total Akrual

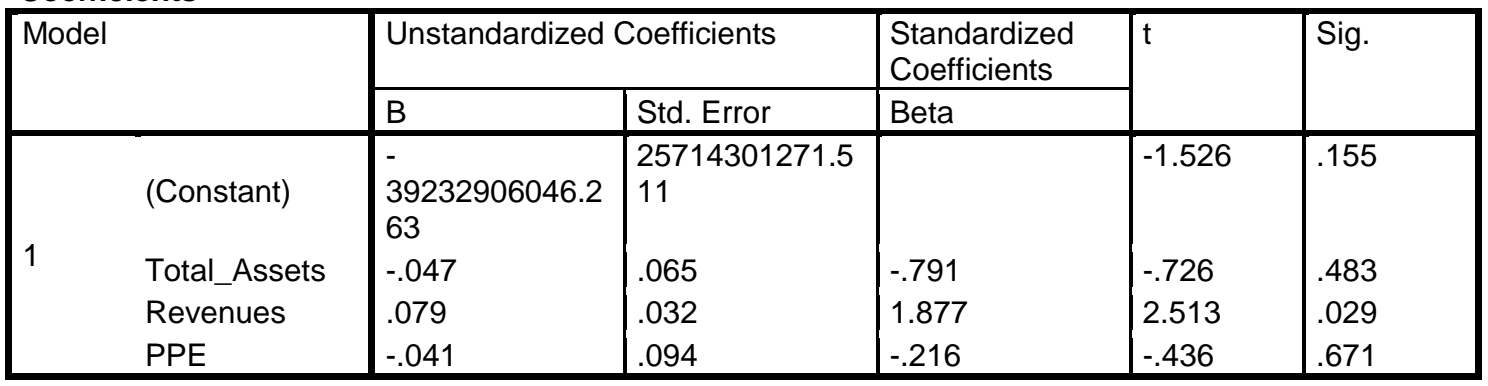

a. Dependent Variable: Total Akrual

Sumber: Hasil Output SPSS

b. Untuk mencari koefisien $\alpha$ dalam NDACC (Nondiscretionary Accrual)

Tabel 4.6. Koefisien dalam Non Discretionary Accrual

Coefficients $^{\mathrm{a}}$

\begin{tabular}{|ll|l|l|l|l|l|}
\hline \multicolumn{2}{|l|}{ Model } & \multicolumn{2}{|l|}{ Unstandardized Coefficients } & $\begin{array}{l}\text { Standardized } \\
\text { Coefficients }\end{array}$ & \multirow{2}{*}{ Sig. } \\
\cline { 3 - 5 } & & $\mathrm{B}$ & Std. Error & Beta & & \\
\hline \multirow{2}{*}{1} & (Constant) & -2.093 & 2.750 & & -.761 & .463 \\
& Total_Assets & $1.174 \mathrm{E}-012$ & .000 & .280 & .268 & .794 \\
& Rev-Rec & $2.525 \mathrm{E}-011$ & .000 & 1.614 & 2.572 & .026 \\
& PPE & $-2.017 \mathrm{E}-011$ & .000 & -1.634 & -2.411 & .035 \\
\hline
\end{tabular}

a. Dependent Variable: Non Discretionary accrual

Sumber: Hasil Output SPSS

6. Jika kedua koefisien telah ditemukan, selanjutnya masukkan rumus model Jones 1991 untuk mengetahui nilai Non Discretionary Accrual dalam perusahaan.

Tabel 4.7. The Jones Model 


\begin{tabular}{|c|c|c|}
\hline Nama Perusahaan & Jones Model 2015 & Jones Model 2016 \\
\hline ADES & $-0,088643261$ & 2,871599941 \\
\hline AISA & $-0,03706658$ & $-7,044344762$ \\
\hline ALTO & $-0,2124675$ & $-21,38207925$ \\
\hline CEKA & $-0,203525969$ & 27,52663135 \\
\hline DLTA & $-0,469796293$ & 2,70216331 \\
\hline ICBP & $-0,053141422$ & $-2,876921491$ \\
\hline INDF & $-0,115247403$ & $-9,162397238$ \\
\hline MLBI & $-0,33612614$ & $-3,620536515$ \\
\hline MYOR & $-0,100288224$ & 10,64391402 \\
\hline PSDN & $-0,303677869$ & $-12,53473641$ \\
\hline ROTI & $-0,240010162$ & $-17,7752211$ \\
\hline SKBM & $-0,390360408$ & $-9,033553716$ \\
\hline SKLT & $-0,031444175$ & $-13,99054473$ \\
\hline STTP & $-0,068960884$ & $-20,72397973$ \\
\hline ULTJ & $-0,033908345$ & $-5,551590625$ \\
\hline
\end{tabular}

7. Kemudian masukkan rumus yang terakhir model Jones Modifikasi untuk mengetahui nilai Non Discretionary Accrual dalam perusahaan.

Tabel 4.8. The Modified Jones Model

\begin{tabular}{|c|c|c|}
\hline Nama Perusahaan & Modified Jones 2015 & Modified Jones 2016 \\
\hline ADES & $-1,75 \mathrm{E}-08$ & $-1,26 \mathrm{E}-08$ \\
\hline AISA & $-8,59 \mathrm{E}-09$ & $-6,92 \mathrm{E}-09$ \\
\hline ALTO & $-9,21 \mathrm{E}-09$ & $-1,03 \mathrm{E}-08$ \\
\hline CEKA & $-2,92 \mathrm{E}-09$ & $-3,99 \mathrm{E}-09$ \\
\hline DLTA & $-4,56 \mathrm{E}-10$ & $-1,88 \mathrm{E}-09$ \\
\hline ICBP & $-5,30 \mathrm{E}-09$ & $-5,38 \mathrm{E}-09$ \\
\hline INDF & $-6,03 \mathrm{E}-09$ & $-5,70 \mathrm{E}-09$ \\
\hline MLBI & $-9,48 \mathrm{E}-09$ & $-1,32 \mathrm{E}-08$ \\
\hline MYOR & $-5,58 \mathrm{E}-09$ & $-7,57 \mathrm{E}-09$ \\
\hline PSDN & $-7,81 \mathrm{E}-09$ & $-9,98 \mathrm{E}-09$ \\
\hline ROTI & $-1,73 \mathrm{E}-08$ & $-1,38 \mathrm{E}-08$ \\
\hline SKBM & $-1,14 \mathrm{E}-08$ & $-1,35 \mathrm{E}-08$ \\
\hline SKLT & $-9,52 \mathrm{E}-09$ & $-1,75 \mathrm{E}-08$ \\
\hline STTP & $-1,22 \mathrm{E}-08$ & $-1,17 \mathrm{E}-08$ \\
\hline ULTJ & $-8,48 \mathrm{E}-09$ & $-6,04 \mathrm{E}-09$ \\
\hline
\end{tabular}

8. Hasil dari keempat rumus dalam model-model yang ada telah diperoleh.

\subsection{Pembahasan}

1. The Healy Model

Dari tabel 4.3 dapat dilihat bahwa ditahun 2015 semua perusahaan yang menjadi sampel penelitian melakukan manajemen laba dengan cara menurunkan laba perusahaan, hal ini ditunjukkan dengan perhitungan model yang hasilnya negatif. Kemudian ditahun 2016 sebagian besar perusahaan menurunkan laba, dan lima diantaranya melakukan manajemen laba dengan cara menaikkan laba perusahaan.

2. The Angelo Model

Dari tabel 4.4 hasilnya sama persis dengan The Healy Model, baik untuk tahun 2015 dan 2016.

3. The Jones Model 
Tabel 4.7 untuk tahun 2015 perusahaan melakukan manajemen laba dengan menurunkan laba, dan di tahun 2016 terdapat lima perusahaan yang menaikkan laba dan sisanya menurunkan laba perusahaan. Namun untuk model Jones ini, perhitungan yang dihasilkan jauh berbeda dengan kedua model sebelumnya, dimana hasilnya jauh lebih besar mengukur adanya manajemen laba pada perusahaan yang menjadi sampel.

4. The Modified Jones Model

Untuk tabel 4.8 hasil dari perhitungan menunjukkan bahwa semua perusahaan ditahun 2015 dan tahun 2016 melakukan manajemen laba dengan cara menurunkan laba perusahaan.

Table 4.9. Hasil Perhitungan Empat Model Manajemen Laba Tahun 2015

\begin{tabular}{|c|r|r|r|r|r|}
\hline $\begin{array}{c}\text { Nama } \\
\text { Perusahaan }\end{array}$ & Tahun & Healy Model & Angelo Model & Jones Model & $\begin{array}{c}\text { Modified } \\
\text { Jones Model }\end{array}$ \\
\hline ADES & 2015 & $-0,019131847$ & $-0,019131847$ & $-0,088643261$ & $-1,75 \mathrm{E}-08$ \\
\hline AISA & 2015 & $-0,003449343$ & $-0,003449343$ & $-0,03706658$ & $-8,59 \mathrm{E}-09$ \\
\hline ALTO & 2015 & $-0,037886833$ & $-0,037886833$ & $-0,2124675$ & $-9,21 \mathrm{E}-09$ \\
\hline CEKA & 2015 & $-0,04833152$ & $-0,04833152$ & $-0,203525969$ & $-2,92 \mathrm{E}-09$ \\
\hline DLTA & 2015 & $-0,054720125$ & $-0,054720125$ & $-0,469796293$ & $-4,56 \mathrm{E}-10$ \\
\hline ICBP & 2015 & $-0,022468897$ & $-0,022468897$ & $-0,053141422$ & $-5,30 \mathrm{E}-09$ \\
\hline INDF & 2015 & $-0,005856507$ & $-0,005856507$ & $-0,115247403$ & $-6,03 \mathrm{E}-09$ \\
\hline MLBI & 2015 & $-0,189293297$ & $-0,189293297$ & $-0,33612614$ & $-9,48 \mathrm{E}-09$ \\
\hline MYOR & 2015 & $-0,105511039$ & $-0,105511039$ & $-0,100288224$ & $-5,58 \mathrm{E}-09$ \\
\hline PSDN & 2015 & $-0,031956044$ & $-0,031956044$ & $-0,303677869$ & $-7,81 \mathrm{E}-09$ \\
\hline ROTI & 2015 & $-0,132985161$ & $-0,132985161$ & $-0,240010162$ & $-1,73 \mathrm{E}-08$ \\
\hline SKBM & 2015 & $-0,034181058$ & $-0,034181058$ & $-0,390360408$ & $-1,14 \mathrm{E}-08$ \\
\hline SKLT & 2015 & $-0,028492758$ & $-0,028492758$ & $-0,031444175$ & $-9,52 \mathrm{E}-09$ \\
\hline STTP & 2015 & $-0,005374603$ & $-0,005374603$ & $-0,068960884$ & $-1,22 \mathrm{E}-08$ \\
\hline ULTJ & 2015 & $-0,050156403$ & $-0,050156403$ & $-0,033908345$ & $-8,48 \mathrm{E}-09$ \\
\hline SUIJ
\end{tabular}

Sumber: Data yang diolah dari Laporan Keuangan perusahaan

Table 4.10. Hasil Perhitungan Empat Model Manajemen Laba Tahun 2016

\begin{tabular}{|c|c|r|r|r|r|}
\hline $\begin{array}{c}\text { Nama } \\
\text { Perusahaan }\end{array}$ & Tahun & \multicolumn{1}{c|}{ Healy Model } & \multicolumn{1}{c|}{ Angelo Model } & \multicolumn{1}{c|}{ Jones Model } & $\begin{array}{c}\text { Modified } \\
\text { Jones Model }\end{array}$ \\
\hline ADES & 2016 & $-0,130362632$ & $-0,130362632$ & 2,871599941 & $-1,26 \mathrm{E}-08$ \\
\hline AISA & 2016 & 0,028214167 & 0,028214167 & $-7,044344762$ & $-6,92 \mathrm{E}-09$ \\
\hline ALTO & 2016 & $-0,039776583$ & $-0,039776583$ & $-21,38207925$ & $-1,03 \mathrm{E}-08$ \\
\hline CEKA & 2016 & 0,049541256 & 0,049541256 & 27,52663135 & $-3,99 \mathrm{E}-09$ \\
\hline DLTA & 2016 & $-0,005145069$ & $-0,005145069$ & 2,70216331 & $-1,88 \mathrm{E}-09$ \\
\hline ICBP & 2016 & $-0,035905143$ & $-0,035905143$ & $-2,876921491$ & $-5,38 \mathrm{E}-09$ \\
\hline INDF & 2016 & $-0,02078476$ & $-0,02078476$ & $-9,162397238$ & $-5,70 \mathrm{E}-09$ \\
\hline MLBI & 2016 & $-0,126777076$ & $-0,126777076$ & $-3,620536515$ & $-1,32 \mathrm{E}-08$ \\
\hline MYOR & 2016 & 0,064302232 & 0,064302232 & 10,64391402 & $-7,57 \mathrm{E}-09$ \\
\hline PSDN & 2016 & $-0,098471288$ & $-0,098471288$ & $-12,53473641$ & $-9,98 \mathrm{E}-09$ \\
\hline ROTI & 2016 & $-0,049855478$ & $-0,049855478$ & $-17,7752211$ & $-1,38 \mathrm{E}-08$ \\
\hline SKBM & 2016 & 0,073748663 & 0,073748663 & $-9,033553716$ & $-1,35 \mathrm{E}-08$ \\
\hline SKLT & 2016 & 0,05039655 & 0,05039655 & $-13,99054473$ & $-1,75 \mathrm{E}-08$ \\
\hline STTP & 2016 & 0,004162703 & 0,004162703 & $-20,72397973$ & $-1,17 \mathrm{E}-08$ \\
\hline ULTJ & 2016 & $-0,019571494$ & $-0,019571494$ & $-5,551590625$ & $-6,04 \mathrm{E}-09$ \\
\hline
\end{tabular}

Sumber: Data yang diolah dari Laporan Keuangan perusahaan

5. KESIMPULAN DAN SARAN

5.1. Kesimpulan

Hasil dari penelitian ini dapat disimpulkan bahwa: 
1. Model Healy mendeteksi semua perusahaan ditahun 2015 melakukan manajemen laba dengan menurunkan laba perusahaan. Ditahun 2016 lima perusahaan melakukan manajemen laba dengan menaikkan laba perusahaan, dan sisanya melakukan manajemen laba dengan menurunkan laba perusahaan.

2. Model Angelo hasilnya sama persis dengan Model Healy, untuk tahun 2015 dan tahun 2016.

3. Model Jones mendeteksi ditahun 2015 semua perusahaan melakukan manajemen laba dengan menurunkan laba perusahaan. Dan ditahun 2016 terdapat lima perusahaan yang melakukan manajemen laba dengan menurunkan laba perusahaan dan sisanya melakukan manajemen laba dengan menurunkan laba perusahaan.

4. Model Jones Modifikasi mendeteksi manajemen laba untuk tahun 2015 dan tahun 2016, hasilnya semua perusahaan melakukan manajemen laba dengan cara menurunkan laba perusahaan

5. Berdasarkan pengamatan yang ditemukan dalam penelitian maka dapat dilihat bahwa semua perusahaan yang menjadi objek penelitian melakukan manajemen laba, baik dengan menurunkan atau menaikkan laba perusahaan.

\subsection{Saran}

Berdasarkan kesimpulan di atas diharapkan penelitian selanjutnya dapat menyajikan hasil penelitian yang berkualitas dengan adanya saran-saran mengenai beberapa hal :

1. Untuk penelitian selanjutnya diharapkan untuk meneliti rentang waktu lebih dari dua tahun laporan keuangan, agar data yang terhitung bukan hanya satu tahun saja sehingga hasil analisinya tidak maksimal.

2. Perusahaan sebaiknya tidak melakukan manajemen laba dalam laporan keuangan karena dapat merugikan para pembaca laporan keuangan serta tidak merugikan investor.

3. Diharapkan bagi para pemegang saham mayoritas tidak meminta jajaran manajer untuk melakukan manajemen laba yang menguntungkan pemegang saham mayoritas dan manajemen, maka pemengang saham minoritas dan pasar saham akan mendiskonkan harga saham perusahaan yang justru akan merugikan pemegang saham mayoritas itu sendiri.

\section{DAFTAR PUSTAKA}

Abdurrahim, Ahim. Mendeteksi Ernings Management. Jurnal Akuntansi \& Investasi. Vol. 1. (15-29)

Anggie Febriyanti. 2014. Manajemen Laba: Pro-Kontra Pemaknaan Antara Kreditur Dan Debitur Dalam Proses Pembiayaan Kredit. Jurnal.

Arikuntoro, Suharsimi. 2002. Prosedur Penelitian Suatu Pendekatan dan Praktek. Jakarta: Rineka Cipta.

Astri Faradila. 2013. Analisis Manajemen Laba Pada Perbankan Syariah. Jurnal.

Cinthia Valle Ruiz. 2016. Literature review of earnings management: Who, why, when, how and what for?. Jurnal.

Dewi Saptantinah Puji Astuti. Review Penelitian Tentang Earnings Management Terhadap Kinerja Perusahaan. Jurrnal.

Dian Agustia. 2013. Pengaruh Faktor Good Corporate Governance, Free Cash Flow, dan Leverage Terhadap Manajemen Laba. Jurnal.

Dye, R. 1988. Earnings Management in an Overlapping Generations Model, Journal of Accounting Research, (Autumn), 195-235. 
Francis Pol C, Lim, (2013). Inpact Of Informatian Technology On Accounting System,Jurnal Of Multimedia Services Convergent With Art, Humanities And Sociology Vol. 3 (2):93-106.

Ghozali, Imam. 2011. Aplikasi Analisis Multivariate dengan Program SPSS. Semarang : BP Universitas Diponegoro.

Gordon, B. Horwitz, and P. Meyer. 1966. Accounting Measurement and Normal Growth of the Firm. Research in Accounting Measurement. (August). 141-161.

Gumanti, Tatang Ary. 2000. Earnings Management: Suatu Telaah Pustaka. Jurnal Akuntansi dan Keuangan 2 No. 2: 104-115.

Haga Badia Sebayang. 2014. Analisis Perbandingan Model Pengukuran Manajemen Laba. Jurnal.

Healy, P. M. \& Wahlen, J. M. 1999. A Review of The Earnings Management Literature and Its Implications for Standard Setting. Accounting Horizons, 13(4): 365-383.

Horwitz, B. and D. Shabahang. 1971. Published Corporate Accounting Data and General Wage Increases of the Firm. The Accounting Review. (April). 243-252.

I Nyoman Wijana Asmara Putra. Manajemen Laba: Perilaku Manajemen Opportunistic Atau Realistic?. Jurnal.

Ilham Firdaus. 2013. "Pengaruh Asimetri Informasi dan Capital Adequacy Ratio Terhadap Manajemen Laba (Studi Empiris Pada Perusahaan Perbankan yang Listing di Bursa Efek Indonesia)". Jurnal.

Krismiaji dan Y Anni Aryani. 2011. Akuntansi Manajemen Edisi Kedua. Penerbit : UPP STIM YKPN.

Kuncoro, Mudrajat. 2003. Metode Riset untuk Bisnis \& Ekonomi, Bagaimana Meneliti \& Menulis Tesis. Erlangga. Jakarta.

Kym Marcel Martins Ardison. The Effect Of Leverage On Earnings Management In Brazil. Jurnal.

Milles, Mattew B., dan A. Michael Huberman. 2014. Analisis Data Kualitatif. Univeristas Indonesia.

Meolong, L.J. 2011. Metodologi Penelitian Kualitatif Edisi Revisi. Bandung. PT Remaja Rosdakarya.

Muliati, N. K. 2011. "Pengaruh Asimetri Informasi dan Ukuran Perusahaan pada Praktik Manajemen Laba di Perusahaan Perbankan yang Terdaftar di Bursa Efek Indonesia”. Jurnal.

Md. Musfiqur Rahman. 2013. Techniques, Motives and Controls of Earnings Management. Jurnal.

Nieken Herma Sari, 2014. Revenue Discretionary Model Pengukuran Manajemen Laba: Berdasarkan Sektor Industri Manufaktur di Bursa Efek Indonesia. Jurnal.

Patricia M. Dechow. 1995. Detecting Earnings Management. Jurnal.

Priyati, Novi. 2013. Pengantar Akuntansi. Penerbit: Indeks Jakarta.

Rahmawati., dkk. 2006. "Pengaruh Asimetri Informasi Terhadap Praktik Manajemen Laba pada Perusahaan Perbankan Publik yang Terdaftar Di Bursa Efek Jakarta”. Simposium Nasional Akuntansi IX. Padang.

Restuwulan. 2013. "Pengaruh Asimetri Informasi dan Ukuran Perusahaan Terhadap Manajemen Laba (Penelitian Pada Perusahaan di Sektor Industri Food an Beverages yang Terdapat di Bursa Efek Indonesia Tahun 2009-2011)”. Jurnal.

Richardson, Vernon J. 1998. Information Asymmetry and Earning Management: Some Evidence. Working Paper.

Riris Rollyna Gultom. 2016. Model Manajemen Laba Stubben, Tata Kelola Dan Nilai Perusahaan Industri Dasar Dan Kimia Di Indonesia. Jurnal. 
Ronen, J. and Sadan, S. 1975. Classificatory Smoothing: Alternative Income Models, Journal of Accounting Research, (Spring), 133-149.

Sadeli, Lili, 2015. Dasar-Dasar Akuntansi. Edisi Pertama, Bumi Aksara Jakarta.

Scott, W. R. 2006. Financial Accounting Theory. 4th Edition. Canada: Person Education. Sharma, V. D., Sharma, D. S., \& Ananthanarayanan, U. 2011. Client Importance and Earnings Mana-gement: The Moderating Role of Audit Com-mittees. AUDITING: A Journal of Practice \& Theory, 30(3): 125-156.

Setiawati, dan Na'im. 2000. Manajemen Laba. Jurnal Ekonomi dan Bisnis Indonesia, Vol. 15, No. $4: 424-441$.

Shalihatunnisa R. 2017. “Analisis Pengaruh Asimetri Informasi, Leverage, Dan Ukuran Perusahaan Terhadap Manajemen Laba (Studi Empiris Pada Perusahaan Yang Terdaftar Di Bei Tahun 2014)". Jurnal.

Siregar, Sylvia Veronica N.P., dan Utama, Siddharta. 2005. "Pengaruh Struktur Kepemilikan, Ukuran Perusahaan, dan Praktik Corporate Governance terhadap Pengelolaan Laba (Earning Management)", Makalah Simposium Nasional Akuntansi VIII Solo 15-16 September 2005.

Sloan, R. G. 1996. Do Stock Prices Fully Reflect Information in Accruals and Cash Flows About Future Earnings?. The Accounting Review 71 : 289-315.

Sugiri, S. 1998. Earning Management: Teori, Model dan Bukti Empiris. Jakarta.

Sugiono. 2015. Metode Penelitian Pendidikan. Bandung: Alfabeta.

Sulistyanto, H. Sri. 2008. Manajemen Laba Teori dan Model Empiris. PT Gramedia Widiasarana Indonesia : Jakarta. Tarigan.

Sweeney, A. 1994. Debt Covenant Violations and Managers' Accounting Responses. Journal of Accounting and Economics, 17(3): 281-308.

Yamaditya, Vanian. 2014. "Pengaruh Asimetri Informasi, Leverage, dan Ukuran Perusahaan Terhadap Praktik Manajemen Laba”. Skripsi. Universitas Diponegoro Semarang. 